\title{
FINDIET 2007 Survey: energy and nutrient intakes
}

\author{
Pirjo Pietinen*, Merja Paturi, Heli Reinivuo, Heli Tapanainen and Liisa M Valsta \\ National Institute for Health and Welfare, PO Box 30, Fl-00270, Helsinki, Finland
}

Submitted 20 July 2009: Accepted 15 March 2010

\begin{abstract}
Objective: The National FINDIET surveys are carried out every 5 years to monitor dietary habits and nutrient intake of the adult Finnish population. The latest survey was carried out in 2007.

Design: Cross-sectional population-based study. Dietary assessment was carried out using $48 \mathrm{~h}$ recall interviews. A picture book of food portions was used to estimate portion sizes and the national Food Composition Database Fineli ${ }^{\circledR}$ to calculate nutrient intakes.

Setting: A representative sample taken in five regions in Finland.

Subjects: A total of 730 men and 846 women aged 24-64 years.

Results: The percentage contribution of fat to the total energy intake was $33 \%$ in men and $31 \%$ in women. The respective percentages for SFA in men and women were $13 \%$ and $12 \%$, respectively, and $0.4 \%$ for trans fatty acids in both genders. The average intakes of folate, vitamin $\mathrm{D}$ and fibre fell below the recommended levels, whereas the average salt intake was somewhat higher than the recommendations. Women's diet was higher in protein, dietary fibre and sucrose compared to that of men.

Conclusions: According to the FINDIET 2007 Survey, the dietary habits of the adult Finnish population have headed in a positive direction overall. However, although the quality of the fats consumed has continued to improve, and the intake of salt has decreased, they still do not meet the recommended levels of intake. Similarly, the average intakes of folate and vitamin D continue to fall below the recommendations. There is also a need to increase fibre intake and to cut down the intake of sucrose.
\end{abstract}

Information on the Finnish diet among adults based on representative population samples is available from 1966 to 1972 , when the Social Insurance Institution carried out a large survey in the whole country ${ }^{(1)}$. At that time the Finnish diet was quite high in total fat, which comprised $38.5 \%$ of energy intake, and it was in particular high in saturated fat $(20.5 \%$ of energy intake). On the basis of the Seven Countries Study among middle-aged men in East and West Finland, salt intake was also very high, $\sim 13-14 \mathrm{~g} / \mathrm{d}$ based on $24 \mathrm{~h}$ urine collections ${ }^{(2)}$. Since then, the Finnish diet has changed remarkably towards a healthier diet, and this has contributed to the decrease in $\mathrm{CHD}^{(3,4)}$. From 1982, the main instrument for monitoring the Finnish diet has been the FINDIET surveys, which are part of the FINRISK studies carried out every 5 years. They are the most important source of information for several purposes: for judging adequacy of the diet in general, to know the differences among different population groups and for nutritional policy purposes. The main results of the FINDIET 2007 Survey are described in the present study. The full report is available on the Internet and includes for the first time features such as distribution curves of different nutrients as well as the nutrient intakes from food supplements ${ }^{(5)}$.

\section{Subjects and methods}

The National FINDIET 2007 Survey was conducted between January and March 2007, and covered five different study regions in Finland. The survey forms part of the National FINRISK 2007 Study, which is a large 5-year population survey set up by the former National Public Health Institute, KTL (since 2009 the National Institute for Health and Welfare, THL), to monitor chronic disease risk factors.

A random sample of adults aged 25-74 years, stratified by sex, area and 10-year age groups, was drawn from the Finnish Population Information System. An invitation letter was sent to the eligible sample ( $n$ 9958) requesting them to attend the study centre in their area, where a group of trained FINRISK study fieldworkers had a reception point. Overall, 63\% of the eligible sample took part in the basic routine physical measurements and examinations. 
Table 1 Mean (SD) daily intakes of energy providing nutrients and fibre among men and women aged 25-64 years: FINDIET 2007 Survey

\begin{tabular}{|c|c|c|c|c|c|c|}
\hline & \multicolumn{2}{|c|}{ Men $(n 730)$} & \multicolumn{2}{|c|}{ Women ( $n$ 846) } & \multirow[b]{2}{*}{$P$ value } & \multirow[b]{2}{*}{ Recommendation } \\
\hline & Mean & SD & Mean & SD & & \\
\hline Energy (MJ) & $9 \cdot 2$ & $3 \cdot 0$ & $6 \cdot 8$ & $2 \cdot 0$ & & \\
\hline Energy (kcal) & 2206 & 705 & 1620 & 483 & $<0.001$ & \\
\hline Protein (g) & $89 \cdot 4$ & $30 \cdot 6$ & $67 \cdot 0$ & $20 \cdot 8$ & & \\
\hline Protein (E\%) & $16 \cdot 8$ & $3 \cdot 7$ & $17 \cdot 2$ & $4 \cdot 1$ & 0.016 & $10-20$ \\
\hline Carbohydrates (g) & $249 \cdot 1$ & 84.9 & $195 \cdot 3$ & $63 \cdot 7$ & & \\
\hline Carbohydrates (E\%) & $47 \cdot 1$ & $8 \cdot 8$ & $50 \cdot 2$ & $8 \cdot 3$ & $<0.001$ & $50-60$ \\
\hline Sucrose (g) & $53 \cdot 5$ & $37 \cdot 1$ & $42 \cdot 9$ & $26 \cdot 3$ & & \\
\hline Sucrose (E\%) & $9 \cdot 7$ & $5 \cdot 9$ & $10 \cdot 5$ & $5 \cdot 1$ & $<0.001$ & $<10$ \\
\hline Dietary fibre $(\mathrm{g})$ & $23 \cdot 7$ & $11 \cdot 3$ & $20 \cdot 7$ & $8 \cdot 9$ & & $25-35$ \\
\hline Dietary fibre (g/MJ) & $2 \cdot 7$ & $1 \cdot 1$ & $3 \cdot 2$ & $1 \cdot 3$ & $<0.001$ & 3 \\
\hline Fat $(\mathrm{g})$ & $83 \cdot 3$ & $35 \cdot 7$ & $58 \cdot 1$ & $24 \cdot 7$ & & \\
\hline Fat $(\mathrm{E} \%)$ & $33 \cdot 1$ & $7 \cdot 9$ & $31 \cdot 2$ & $7 \cdot 4$ & $<0.001$ & $25-35$ \\
\hline Alcohol (g) & $11 \cdot 2$ & $31 \cdot 1$ & $3 \cdot 4$ & $10 \cdot 2$ & & \\
\hline Alcohol (E\%) & $3 \cdot 1$ & $6 \cdot 5$ & $1 \cdot 3$ & $3 \cdot 8$ & $<0.001$ & $<5$ \\
\hline
\end{tabular}

The participants had already filled in a general questionnaire at home, which also included questions on some dietary habits. Those belonging to the FINDIET 2007 Survey subgroup (33\% of the sample) participated also in a dietary interview. Trained interviewers carried out face-to-face $48 \mathrm{~h}$ dietary recall interviews and entered the data using the Finessi software program, the process resulting in 2039 acceptable interviews. A picture book of food portions was given to the respondents to estimate portion sizes $^{(6)}$. In the present study, results concerning only working-aged persons, between 25 and 64 years of age, are reported for the sake of comparison with earlier reports, and for the reason that many recommendations differ between working age and older adults. Thus, the final number of participants studied in here are 730 men (56\% of the original sample) and 846 women (64\%). In a report that can be found on the Internet, the results are also given for the oldest age group ${ }^{(5)}$. In addition to the dietary interview, every other person was asked to keep a $3 \mathrm{~d}$ food diary immediately after the interview in January-March and again between June and October. Altogether, 442 working age persons completed both of these diaries to an acceptable standard.

Dietary data were entered and processed on the Finessi software, an application developed at THL, which uses the Fineli ${ }^{\circledR}$ Food Composition Database. A detailed description of this metholodogy can be found in the article by Reinivuo et al. $^{(7)}$ in this issue. Mean intakes of nutrients were compared to the Finnish Nutritional Recommendations given by the National Nutrition Council ${ }^{(8)}$ (Table 1). Because of the common problem of under-reporting, all the intakes are energy-adjusted, either as percentages of energy or per MJ. In the report, results excluding underreporters are also presented (31\% of men and 38\% of women). The criteria used have been published previously $^{(9)}$. In the present study, only sodium/salt intake is reported both including and excluding under-reporters, since the recommendations are not energy-adjusted but absolute amounts. The usual intake distributions of salt were estimated using both $48 \mathrm{~h}$ dietary recall data and data from food diaries. The calculations were carried out with SIDE (Iowa State University, Center for Survey Statistics and Methodology, version 1.01) software, which uses the Iowa State University method to estimate the usual intakes ${ }^{(10)}$.

The use of food supplements was examined in conjunction with the $48 \mathrm{~h}$ recall. At the recall interview, the respondent was asked whether he/she had taken any food supplements during the past $48 \mathrm{~h}$ study period. Food supplements were identified with the help of a picture booklet containing the 100 most common food supplements available in the market. The contents of these supplements were also in the Fineli ${ }^{\circledR}$ database, and thus, the intakes of vitamins, minerals and fatty acids from supplements could be calculated and added to the dietary intakes.

The differences in nutrient intakes between men and women were tested using the ANOVA, adjusting for age and area. The intake values were log transformed in order to improve normality. The analyses were performed using the SAS statistical software package version $8 \cdot 2$ (SAS Institute Inc., Cary, NC, USA).

\section{Results}

The mean daily energy intake of all men was $9 \cdot 2 \mathrm{MJ} / \mathrm{d}$ $(2206 \mathrm{kcal})$ and that of all women $6 \cdot 8 \mathrm{MJ}(1620 \mathrm{kcal})$. However, when under-reporters were excluded, the respective numbers were $10 \cdot 5 \mathrm{MJ}(2517 \mathrm{kcal})$ and $7 \cdot 9 \mathrm{MJ}$ (1891 kcal). The main composition of the diet was different in men compared to women (Table 1). The percentage contribution of fat to the total energy intake was $33 \%$ in men and $31 \%$ in women. Women's diets were higher in protein, dietary fibre and sucrose compared to that of men, while men consumed more alcohol. The percentages for SFA from energy were also higher in men: $12 \cdot 9 \%$ compared to $12 \cdot 0 \%$ in women (Table 2 ). The share of trans fatty acids was very low, at $0 \cdot 4 \%$ of energy in both genders. The majority of the trans fatty acids, $78 \%$ 
Table 2 Mean (SD) intakes of fatty acids and cholesterol among men and women aged 25-64 years: FINDIET 2007 Survey

\begin{tabular}{|c|c|c|c|c|c|c|}
\hline & \multicolumn{2}{|c|}{ Men $(n 730)$} & \multicolumn{2}{|c|}{ Women ( $n$ 846) } & \multirow[b]{2}{*}{$P$ value } & \multirow[b]{2}{*}{ Recommendation } \\
\hline & Mean & SD & Mean & SD & & \\
\hline Total fatty acids (g) & $76 \cdot 6$ & $32 \cdot 9$ & $53 \cdot 4$ & $22 \cdot 7$ & & \\
\hline Total fatty acids (E\%) & $30 \cdot 4$ & $7 \cdot 3$ & $28 \cdot 7$ & $6 \cdot 8$ & $<0.001$ & 28 \\
\hline SFA (g) & $32 \cdot 5$ & $16 \cdot 1$ & $22 \cdot 6$ & $11 \cdot 3$ & & \\
\hline SFA (E \%) & $12 \cdot 9$ & $4 \cdot 1$ & $12 \cdot 0$ & $3 \cdot 9$ & $<0.001$ & $10^{*}$ \\
\hline MUFA $(\mathrm{g})$ & $30 \cdot 2$ & $14 \cdot 1$ & $20 \cdot 4$ & $9 \cdot 5$ & & \\
\hline MUFA (E \%) & $12 \cdot 0$ & $3 \cdot 5$ & $10 \cdot 9$ & $3 \cdot 2$ & $<0.001$ & $10-15$ \\
\hline PUFA (g) & $14 \cdot 7$ & $7 \cdot 7$ & $10 \cdot 4$ & $5 \cdot 2$ & & \\
\hline PUFA (E \%) & $5 \cdot 9$ & $2 \cdot 2$ & $5 \cdot 7$ & $2 \cdot 2$ & 0.028 & $5-10$ \\
\hline$n-3$ fatty acids $(\mathrm{g})$ & $3 \cdot 1$ & $1 \cdot 8$ & $2 \cdot 2$ & $1 \cdot 2$ & & \\
\hline$n-3$ fatty acids (E\%) & $1 \cdot 2$ & 0.6 & $1 \cdot 2$ & 0.5 & NS & 1 \\
\hline$n-6$ fatty acids $(\mathrm{g})$ & $11 \cdot 4$ & $6 \cdot 3$ & $8 \cdot 1$ & $4 \cdot 4$ & & \\
\hline$n-6$ fatty acids (E\%) & $4 \cdot 5$ & $1 \cdot 9$ & $4 \cdot 4$ & $1 \cdot 9$ & NS & \\
\hline Trans fatty acids (g) & $1 \cdot 0$ & $0 \cdot 6$ & $0 \cdot 7$ & 0.5 & & \\
\hline Trans fatty acids (E\%) & $0 \cdot 4$ & $0 \cdot 2$ & $0 \cdot 4$ & $0 \cdot 2$ & NS & \\
\hline Cholesterol (mg) & 256 & 152 & 176 & $92 \cdot 6$ & $<0.001$ & \\
\hline
\end{tabular}

*The recommendation concerns SFA and trans fatty acids together.

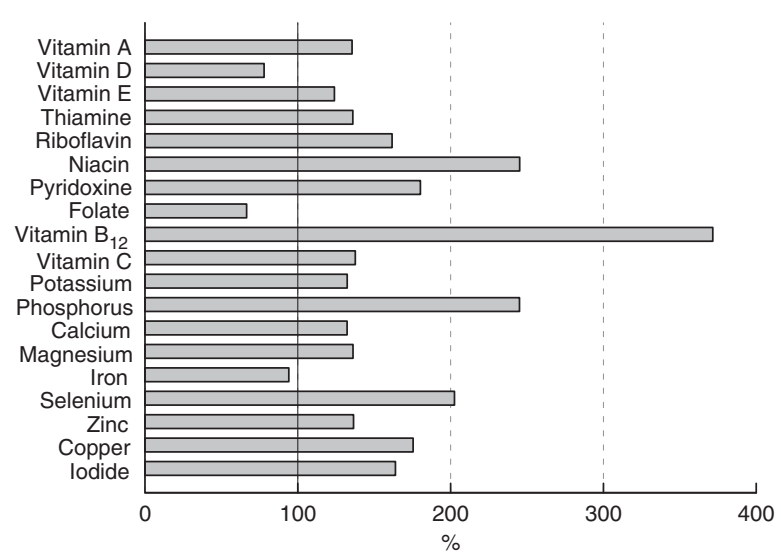

Fig. 1 Mean intake (\% of recommended intake) of vitamins and minerals per unit of energy, for men

in men and $77 \%$ in women, was derived from ruminant animal fats. The intake of PUFA was $5 \cdot 9 \mathrm{E} \%$ in men and $5.7 \mathrm{E} \%$ in women.

On the basis of the questionnaire, $34 \%$ of men reported usually drinking skimmed milk and 36\% low-fat milk, 4\% reported using butter and 49\% low-fat margarines (40-60\% fat) on bread, whereas 50\% reported using oil and $12 \%$ butter in cooking. In women, $41 \%$ reported usually drinking skimmed milk and 25\% low-fat milk, $2 \%$ reported using butter and 51\% low-fat margarines on bread, whereas $59 \%$ reported using oil and $11 \%$ butter in cooking. In addition, $49 \%$ of men and $51 \%$ of women reported using low-fat cheeses $(<17 \%$ fat) daily.

The average intakes of folate and vitamin $\mathrm{D}$ fell below the recommended levels both in men and women (Figs. 1 and 2). The average iron intake was not abundant, either, and did not quite meet the recommendations. The average intakes of other vitamins and minerals met the recommendations except for sodium. The calculated sodium intake was $8.3 \mathrm{~g}$ in men and $6.0 \mathrm{~g}$ in women. However, when under-reporters were excluded, the mean intake was

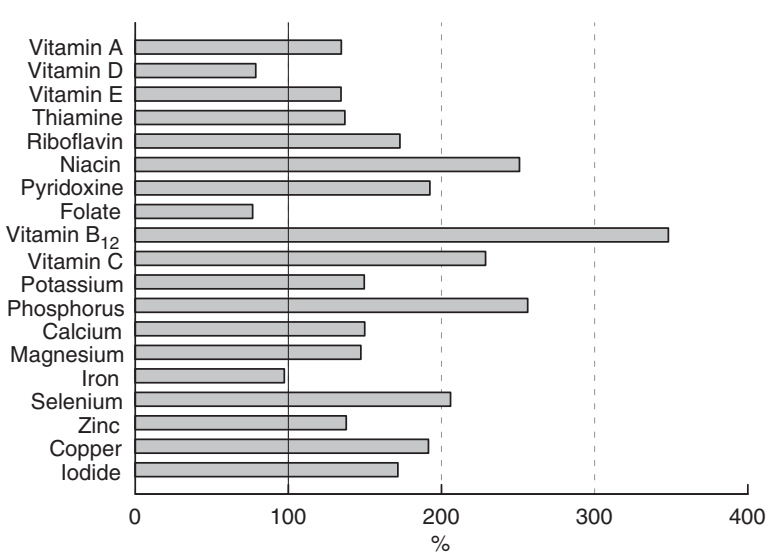

Fig. 2 Mean intake (\% of recommended intake) of vitamins and minerals per unit of energy, for women

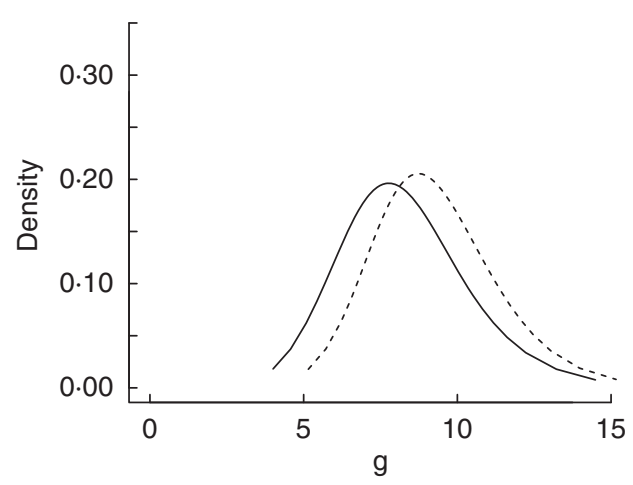

Fig. 3 Intake of salt (NaCl; g/d) from food, for men (-, all; - - -, under-reporters excluded)

$9 \cdot 3 \mathrm{~g}$ in men and $6.8 \mathrm{~g}$ in women. The Finnish recommendations are $7 \mathrm{~g}$ for men and $6 \mathrm{~g}$ for women. The distribution of salt intake with and without under-reporters is shown in Figs. 3 and 4. Similar distributions for other nutrients are shown in the report itself. 


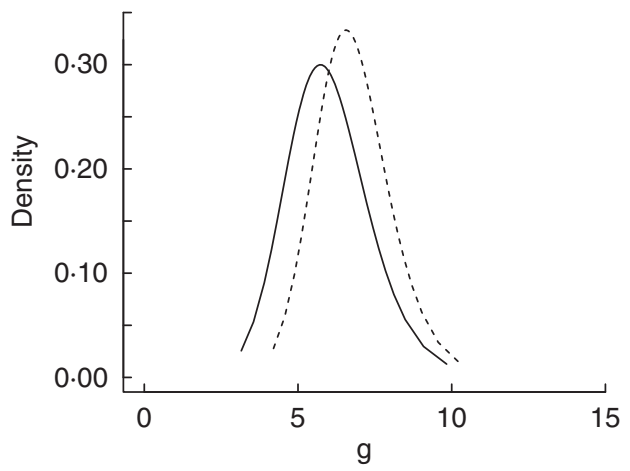

Fig. 4 Intake of salt ( $\mathrm{NaCl} ; \mathrm{g} / \mathrm{d})$ from food, for women (-, all; - - -, under-reporters excluded)

Finnish adults were found to be regular dietary supplement takers (33\% of men and $50 \%$ of women). The most common types of dietary supplements taken were those containing both vitamins and minerals, and those containing fatty acids. Food supplements were important sources of vitamin $\mathrm{D}$, thiamine, riboflavin, niacin, pyridoxine, vitamin $\mathrm{B}_{12}$, vitamin $\mathrm{C}$, and iron. Dietary supplements were targeted poorly, since for almost all vitamins and minerals, the intake from food was equally high or higher among supplement takers than among the non-supplement takers. A typical dietary supplement taker is a well-educated urban woman.

\section{Discussion}

There have been favourable changes in the intakes of fatty acids even during the past 5 -year period. The intake of total fats has decreased from $34.9 \%$ of energy in 2002 to $33 \cdot 1 \%$ in men and from $32 \cdot 4 \%$ to $31 \cdot 2 \%$ in women ${ }^{(11)}$. Thus, the total fat intake level meets the recommendations. The intake of SFA has decreased from $14 \cdot 4 \%$ in men to $12 \cdot 9 \%$ and from $13.6 \%$ to $12 \cdot 0 \%$ in women, and trans fatty acids have decreased from $0.5 \%$ to $0 \cdot 4 \%$ in both genders. The intake of PUFA has increased from $5 \cdot 2 \%$ to $5 \cdot 9 \%$ in men and from $4 \cdot 9 \%$ to $5 \cdot 7 \%$ in women. There has also been a $0 \cdot 2 \%$ unit increase in $n$ - 3 fatty acids in both genders during this time period. These favourable changes are reflected in serum cholesterol levels as has been described in another article of this supplement $^{(12)}$.

The favourable changes in the fatty acid composition of the diet are a reflection of the profound changes in food consumption over many decades, particularly in the consumption of milks and fat spreads. Skimmed milk has become the most popular milk and low-fat margarines mostly based on canola oil, the most popular fat spreads. The consumption of low-fat cheeses has also become popular and their selection and availability is very high. Increased consumption of both canola oil and fish explain the increase in the intake of $n$ - 3 fatty acids.
Women consume less fat but more sucrose and dietary fibre. These gender differences have existed for a long time and can be seen even among school-aged children ${ }^{(13)}$. Women have a higher intake of vitamin $\mathrm{C}$ compared to men, which is a reflection of higher consumption of fruit and vegetables. Part of the higher sucrose intake in women is explained by the natural sucrose in fruit, which our software cannot separate from added sugars. Dietary fibre intake meets the recommendation among women aged $>45$ years because of their higher consumption of whole grains, especially from rye bread.

Intakes of folate and vitamin D are inadequate in both genders. Folate intake could be increased by greater consumption of whole-grain products, especially with increased rye bread consumption. Vitamin D intake is mostly dependent on the consumption of fish and is highest among older persons because of their higher fish consumption. In Finland, fat spreads have been fortified with vitamin D since the 1950 s and liquid milk products since 2003. Although this procedure has increased vitamin D intake, the situation is still not adequately judged by this report as well as studies on the vitamin D status in different population groups ${ }^{(14,15)}$. Currently, an expert group nominated by the National Nutrition Council is trying to find new solutions to improve the situation.

Salt intake has decreased gradually since the late $1970 \mathrm{~s}^{(16,17)}$. Salt intake in the population has been monitored in connection with the FINRISK surveys by $24 \mathrm{~h}$ urine collections, and also in the FINDIET surveys by calculating sodium intake, as in the survey of 2007. Although salt intake was about $13 \mathrm{~g} / \mathrm{d}$ in men and $11 \mathrm{~g} / \mathrm{d}$ in women in 1979, it is now about $8-9 \mathrm{~g} / \mathrm{d}$ in men and about $7 \mathrm{~g} / \mathrm{d}$ in women. Systematic work has been carried out to lower salt intake by educating the public and by working with the food industry to reduce the salt content of processed food. In addition, national legislation was revised to enable the labelling of products with a reduced salt content, such as bread, sausages, other meat products, cheese, breakfast cereals, soups and other prepared foods, having food-specific criteria. This labelling system also forces the producers to label heavily salted products, which has made them almost disappear from the market. This can be used as a model in other countries also, since it has been shown to be a powerful way to influence salt intake in the population ${ }^{(18)}$.

In conclusion, according to the FINDIET 2007 Survey, the dietary habits of the adult Finnish population have headed in a positive direction overall. However, in certain areas, there is still room for improvement. For instance, although the quality of the fats consumed has continued to improve and the average intake of salt has decreased, they still do not quite meet the recommended levels of intake. Similarly, the average intakes of folate and vitamin $\mathrm{D}$ fall below the recommendations. There is also a need to increase fibre intake and to cut down the intake of sucrose. A diet comprised of more unrefined cereals, fish, 
vegetables, fruit and berries, as well as unsaturated fats and less of foods containing high levels of added sugar would help achieve this goal.

\section{References}

1. Hasunen K, Pekkarinen M, Koskinen E et al. (1976) The Food Consumption and Nutrient Intake in Finland from 1966 to 1972 (In Finnish, summary in English). Report of the Social Insurance Institution ML9, Helsinki.

2. Karvonen MJ \& Punsar S (1977) Sodium excretion and blood pressure of west and east Finns. Acta Med Scand 202, 501-507.

3. Pietinen P, Vartiainen E, Seppänen R et al. (1996) Changes in diet in Finland from 1972 to 1992: impact on coronary heart disease. Prev Med 25, 243-250.

4. Laatikainen T, Critchley J, Vartiainen E et al. (2005) Explaining the decline in coronary heart disease mortality in Finland between 1982 and 1997. Am J Epidemiol 162, 764-773.

5. Paturi M, Tapanainen $\mathrm{H}$, Reinivuo $\mathrm{H}$ et al. (editors) (2008) The National FINDIET 2007 Survey (In Finnish, tables, figures and summary in English). Publications of the National Public Health Institute B23/2008. Helsinki: Yliopistopaino; available at http://www.ktl.fi/attachments/ suomi/julkaisut/julkaisusarja_b/2008/2008b23.pdf

6. Ovaskainen M-L, Paturi M, Reinivuo H et al. (2008) Accuracy on the estimation of food servings against the portions in food photographs. Eur J Clin Nutr 62, 674-681.

7. Reinivuo H, Hirvonen T, Ovaskainen M-L et al. (2009) Dietary survey methodology of Findiet 2007 Survey with a risk assessment perspective. Public Health Nutr (in this issue).

8. National Nutrition Council (2005) Suomalaiset ravitsemussuositukset (In Finnish, title in English: Finnish Nutrition Recommendations - Diet and physical activity in balance). Committee report. Helsinki: Edita Publishing Oy; available at http:// www.evira.fi/portal/vrn/en/nutrition_recommendations/
9. Goldberg GR, Black AE, Jebb SA et al. (1991) Critical evaluation of energy intake using fundamental principles of energy physiology: 1. Derivation of cut-off limits to identify under-recording. Eur J Clin Nutr 45, 569-581.

10. Nusser SM, Carriquiry AL, Dodd KW et al. (1996) A semiparametric transformation approach to estimating usual daily intake distributions. J Am Statist Assoc 91, 1440-1449.

11. Männistö S, Ovaskainen M-L \& Valsta L (editors) (2003) The National FINDIET 2002 Study (In Finnish, tables, figures and chapter summaries in English). Publications of the National Public Health Institute B3/2003. Helsinki: Hakapaino Oy; available at http://www.ktl.fi/portal/suomi/ osastot/eteo/yksikot/ravitsemusyksikko/julkaisut/finravinto_ 2002_tutkimuksen_raportti/

12. Valsta LM, Tapanainen H, Laatikainen $\mathrm{T}$ et al. (2009) Explaining the 25-year decline of serum cholesterol by changes in food consumption and use of medication in Finland. Public Health Nutr (in this issue).

13. Hoppu U, Lehtisalo J, Tapanainen H et al. (2009) Dietary habits and nutrient intake of Finnish adolescents. Public Health Nutr (in this issue).

14. Laaksi IT, Ruohola J-PS, Ylikomi TJ et al. (2006) Vitamin D fortification as public health policy: significant improvement in vitamin D status in young Finnish men. Eur J Clin Nutr 60, 1035-1038.

15. Välimäki V-V, Löyttyniemi E \& Välimäki MJ (2007) Vitamin D fortification of milk products does not resolve hypovitaminosis D in young Finnish men. Eur J Clin Nutr 61, 493-497.

16. Laatikainen T, Pietinen P, Valsta L et al. (2006) Sodium in the Finnish diet: 20-year trends in urinary sodium excretion among the adult population. Eur J Clin Nutr 60, 965-970.

17. Reinivuo H, Valsta LM, Laatikainen T et al. (2006) Sodium in the Finnish diet: trends in dietary sodium intake and comparison between intake and 24-hour excretion of sodium. Eur J Clin Nutr 60, 1160-1167.

18. Pietinen P, Valsta LM, Hirvonen T et al. (2008) Labelling the salt content in foods: a useful tool in reducing sodium intake in Finland. Public Health Nutr 11, 335-340. 